of hand"; many hypotheses exist, but none has yet been demonstrated to apply globally. This view is not surprising given the complexity of the carbon cycle, the urgent need to improve our understanding of the cycle and its role in climate change, and the absence of adequate constraints. Then, too, there is the political angle you might want to 'discover' a substantial $\mathrm{CO}_{2}$ sink in your region if this can be used to offset industrial emissions of $\mathrm{CO}_{2}$; on the other hand, this may bring with it restrictions on land use with concomitant economic penalties.

Two earlier analyses of forest growth ${ }^{5,6}$ produced high estimates of $\mathrm{CO}_{2}$ uptake in the temperate and boreal regions of the Northern Hemisphere, and at first sight might seem to have identified these forested regions as the missing sink. Houghton takes issue with these findings, on the basis that they did not properly account for the fate of carbon 'harvested' from the forests - they took account of carbon-consuming regrowth after logging, which has increased substantially in the past 25 years, but not the $\mathrm{CO}_{2}$ released from decay of plant material, whether it rots as debris on the forest floor or gradually oxidizes in final, processed form (say, lumber or paper). In fact, Houghton suspects that the net flux of carbon from such changes in land use may be close to zero. Detailed, mass-conserving biogeochemical models that track carbon from its uptake by the biosphere through its storage and return to the atmosphere will be needed for reliable estimates of the net flux of carbon to the atmosphere.

Houghton also argues that if new plant growth really accounts for a carbon imbalance of $1.5 \mathrm{Gt} \mathrm{C}$ per year, this growth rate should be detectable from forest surveys, whether it occurs in the northern temperate zones alone or around the world. Available forest surveys should be scrutinized; but questions about how accurate and representative they are make it unlikely that these surveys alone will give the definitive answer on the size of the forest carbon sink.

Dai and Fung ${ }^{4}$, using empirical models for net primary production and soil respiration in conjunction with global temperature and precipitation data, have investigated the effects of climate change on $\mathrm{CO}_{2}$ uptake for the period 1940-88, finding that variations in temperature and precipitation could have produced a cumulative carbon sink of $20 \pm 5 \mathrm{Gt} \mathrm{C}$ for the period 1950-84. They ignored the effect of increases in plant growth associated with increasing atmospheric $\mathrm{CO}_{2}$, the ' $\mathrm{CO}_{2}$ fertilization effect'.

If Dai and Fung are correct in their assessment of the importance of climate change for the biospheric uptake of $\mathrm{CO}_{2}$, then understanding this mechanism will be vital for accurate prediction of future $\mathrm{CO}_{2}$ concentrations. But as they acknow- ledge, they used a greatly simplified empirical model to calculate the flux of carbon between the biosphere and the atmosphere that only takes into account changes in temperature and precipitation. It does not account for the dynamics of carbon storage, thereby linking net primary productivity (NPP) to respiration, or other factors limiting NPP. They used a modified form of the Miami model ${ }^{7}$ to calculate NPP, which they reduced to fit a theoretically derived NPP distribution for regions outside the tropics, whereas King et al. ${ }^{8}$ found that no such modification was required for their study region, $64-90^{\circ} \mathrm{N}$, when compared with available observations of NPP. No attempt was made to track carbon through the storage pools, a critical factor in estimating carbon sequestration $^{8,9}$, so the mass of carbon available for oxidation was not taken into account. Much of the carbon uptake identified by Dai and Fung is probably already back in the atmosphere, making their estimate an upper bound for the magnitude of this biospheric sink.

Dai and Fung's result is much more sensitive to climate change than that found by Melillo et al. ${ }^{10}$, who use a more detailed model to predict NPP. Melillo et al. found very little change in NPP associated with five different climate forecasts derived from doubled- $\mathrm{CO}_{2}$ climate model runs. These all include substantial increases in temperature and precipitation. Several studies ${ }^{9-11}$ concluded that changes in the atmospheric $\mathrm{CO}_{2}$ concentration, rather than changes in climate, produce the greatest change in NPP, particularly in the tropics, and the largest biospheric sink for carbon. Investigations of the long-term change in carbon uptake by the biosphere must also take into account how vegetation patterns will change in response to climate $e^{10,12}$ and decisions on land use.

Until we can do such an analysis, predictions of future $\mathrm{CO}_{2}$ concentrations and the efficiency of policies directed at stabilizing atmospheric $\mathrm{CO}_{2}$ must remain questionable.

John Taylor is in the Centre for Resource and Environmental Studies, The Australian National University, Canberra, Australian Capital Territory 2601, Australia.

1. Broecker, W. S. et al. Science 206, 409-418 (1979)

2. Siegenthaler. U. \& Sarmiento J. L. Nature $\mathbf{3 6 5}, 119$ 125 (1993)

3. Houghton, R. A. Glob. biogeochem. Cycles 7, 611-617 (1993).

4. Dai. A. \& Fung, I. Y. Glob. biogeochem. Cycles 7 599-609 (1993)

5. Kauppi, P. E. et al. Science 256, 70-74 (1992)

6. Sedjo. R. A. Ambio 21, 274-277 (1992)

7. Lieth. H. in Primary Productivity of the Biosphere (eds Lieth, H. \& Whittaker, R. H.) 237-263 (Springer, New York, 1975)

8. King, A. W. et al. Glob. biogeochem. Cycles 3, 337-361 (1989).

9. Gifford, R. M. Adv. Bioclimatol. 1, 24-58(1992). 10. Melillo, J. M. et al. Nature 363, 234-240 (1993).

11. Taylor, J. A. \& Lloyd, J. Aust. J. Bot. 40, 407-418 (1992)

12. Prentice, I. C et al. J. Biogeogr. 19, 117-134 (1992).

\section{Spiritual journey}

LAST week Daedalus proposed a way of measuring the weight of the soul. It required the subject to die in an instrumented container whose mechanical constants were continually computer-refined from transducer data. As the soul left the body, its recoil would reveal its direction, velocity and spin; the change in weight would give its mass. Traditional theology is silent on the spin of the soul, though it may predict that the soul of a sinner would depart downwards, and might weigh less than that of a righteous believer. Such experiments could settle this and other speculations. Does everybody have a soul? Do its mass, spin and speed mirror its owner in any way? Does it leave at the moment of clinical death, or can it depart earlier, leaving the body in a soulless state of animal existence? Indeed, do animals have souls, and if so which ones, and how do the mechanical properties of their souls vary with species? Many have died, or inflicted death, for much less fundamental points of theology.

Even so, an extensive programme of inherently lethal experiments is ethically worrying. The converse approach may be more acceptable: that of detecting the weight-gain and mechanical impact of a soul entering a female subject as she becomes pregnant. The study need not invade anyone's sexual privacy. Many theologians argue that the soul enters the fetus a week or so after conception. This is the point when it has acquired individuality; for if divided, it will no longer develop into twins. It is clearly worthwhile to establish this moment accurately. If the soul turns out to enter the fetus quite late in pregnancy, the religious arguments against contraception and early abortion will be neatly disproved.

Daedalus, however, would like to detect the soul in situ, not merely at its moment of arrival or departure. He points out that normal material objects have identical inertial and gravitational masses. The soul may not. In that case, a creature with a soul would fall in vacuo with an acceleration slightly different from $g$, and as a compound pendulum would swing at a slightly different frequency from the equivalent distribution of dead matter. The effect would be extremely small. It might be detectable as a slight orbital deviation in a manned spacecraft, due to the anomalous inertial mass of the souls aboard it. But near-Earth orbits, perturbed by atmospheric drag, are probably too uncertain to reveal the effect. Accordingly, it provides perhaps the only scientific justification for a manned spaceflight to Mars. David Jones

NATURE · VOL 366 - 9 DECEMBER 1993 